\title{
Analyzing the relative efficiency of China's Yangtze River port system
}

\author{
Shilin $\mathrm{Ye}^{1,2} \cdot$ Xinhua $Q i^{1,2} \cdot$ Yecheng Xu ${ }^{3}$
}

Published online: 24 January 2020

(c) The Author(s) 2020

\begin{abstract}
In spite of the rapid growth of the Yangtze River port system (YRPS) in recent years, knowledge regarding the efficiency characteristics of these ports along the Yangtze River is still limited. This article evaluates the relative efficiency of 22 major ports along the Yangtze River from 2010 to 2016 by using the novel super slacks-based measure (super-SBM) model and the Malmquist productivity index. The YRPS showed a relatively low level of average technical efficiency in 2016, and the technical efficiency values of these ports increased generally from upstream to downstream. In terms of returns to scale, the ports of Shanghai, Nantong, and Suzhou should pay attention to resource allocation, technological advancement, and institutional innovation in the future. The remaining 19 ports, however, should increase investment in the optimization of production-capacity structures, the upgrading of terminal equipment, the improvement of consolidation and distribution systems, channel regulation, and information sharing among terminals. Our results also show that the production technology, resource utilization, enterprise management, and scale economies of the YRPS improved during 2010-2016, and this significantly enhanced the total factor productivity (TFP). Based on these findings, we propose several development strategies for the YRPS, such as improving the consolidation and distribution systems of ports, encouraging the cross-regional integration of port and shipping enterprises, strengthening the coconstruction and sharing of infrastructure, and optimizing the hub-and-spoke network of the YRPS.
\end{abstract}

Keywords River port · Port efficiency $\cdot$ Super-SBM model $\cdot$ Malmquist productivity index $\cdot$ Yangtze River port system

Xinhua Qi

fjqxh@fjnu.edu.cn

1 Key Laboratory for Humid Subtropical Eco-geographical Processes of the Ministry of Education, Fujian Normal University, Fuzhou, People's Republic of China

2 School of Geographical Sciences, Fujian Normal University, Fuzhou, People's Republic of China

3 School of Forestry and Wildlife Sciences, Auburn University, Auburn, USA 


\section{Introduction}

As critical nodes and potential bottlenecks in the international logistical network, ports play a pivotal role in global trade, particularly as hubs, facilitating intermodal transfers at intersections with other modes of transport. Thanks to rapid economic globalization and the development of modern logistics, the function of ports has evolved from a traditional waterway transit node to a complex logistics center, integrating transportation, law, information, industry, trade, and other systems (Drewe and Janssen 1998). Currently, ports are deeply embedded in global production, transport, distribution and sales, forming a vital link in the global value and supply chain (Robinson 2002). Ports have become one of the main engines for the promotion of regional economic development and an important contributor to a nation's international competitiveness (Suykens and Van de Voorde 1998; Chin and Tongzon 1998). However, some factors, including global economic integration, improvements in supply chain management methods, the rapid growth of transport infrastructures, and intermodal transportation, have caused increasingly fierce competition among ports worldwide, obliging those ports to provide more value-added logistics services and continuously improve their operational efficiency (Wang and Cullinane 2006; Verhoeven 2010; Da Silva and Rocha 2012). Accordingly, improving port efficiency has become a critical task for local governments, particularly in rapidly developing regions. This increasing competitive pressure on ports as well as the demands of regional economic development have made port efficiency an important topic among scholars since the second half of the 1990s (Wang et al. 2004; González and Trujillo 2008).

In recent years, the large economic centers and distant hinterland regions of the Yangtze River economic belt (YZREB) have been more closely connected, with the continuous improvement of comprehensive transportation systems, especially the development of transport along inland waterways, which has promoted the rapid development of the regional economy along the YZREB. Currently, the developments of the Yangtze River's shipping markets and port systems have received extensive attention from academia, with numerous research studies. These studies principally cover the evolution of the spatial structure of the port systems, the relationship between ports and cities, the optimization of cargo consolidation and distribution systems, etc. (Zhao et al. 2019). However, we still lack sufficient understanding of the efficiency characteristics of river ports along the Yangtze (Yuen et al. 2013; Barros et al. 2016). Additionally, quantitative analysis of these ports' efficiency is required. In the present work, the efficiency of the Yangtze River port system (YRPS) is measured by using the super slacks-based measure (super-SBM) model (Tone 2002) and Malmquist productivity index (Malmquist 1953). We expect this study to provide a reasonable decision-making basis for port operations and promote the synergetic development of river port systems.

The remainder of this manuscript is organized as follows: Section 2 reviews the existing studies on port efficiency. Section 3 presents the characteristics of the Yangtze River port system. Section 4 details the methodology and describes the data. Section 5 presents the results and discussion, and Sect. 6 describes the conclusions. 


\section{Literature review of port efficiency analysis}

Port efficiency, which deeply influences port competitiveness and determines whether a port can survive in a fiercely competitive environment, has been broadly investigated. After reviewing the existing literature, we can determine that efficiency mainly focuses on the following two issues.

First, how can port efficiency be measured comprehensively? A number of approaches to measure port efficiency have been adopted in existing literature. In the early days, efficiency measurement was usually based on single or multiple indicators, such as single-factor productivity (De Monie 1987), total factor productivity (Kim and Sachish 1986), or multiple regression analysis (Tongzon 1995). These measurements are valuable for describing port efficiency from one or more dimensions and are easy to apply. However, their limitations are also obvious. Port efficiency cannot be easily fully represented by a single indicator, considering that the information delivered by any single indicator is insufficient. On the other hand, the main weakness of multiple indicators lies in the difficulty of judging whether variations in the different indicators improve or reduce port efficiency (Cullinane and Wang 2006a).

Several more reasonable and persuasive approaches have been suggested for a more comprehensive assessment of port efficiency. Among them, data envelopment analysis (DEA) (Tongzon 2001; Barros 2003; Cullinane et al. 2005; Yuen et al. 2013; Beuren et al. 2018) and stochastic frontier analysis (SFA) (Liu 1995; Coto-Millan et al. 2000; Cullinane and Song 2003; Pagano et al. 2013; Serebrisky et al. 2016) have been widely used (Cullinane et al. 2006; Panayides et al. 2009; Merkel and Holmgren 2017); For example, Barros and Athanassiou (2004) applied DEA to estimate the relative efficiency of two Greek and four Portuguese seaports from 1998 to 2000. These authors suggested that scale economies and privatization improve performance. Similarly, Beuren et al. (2018) evaluated and compared the efficiency of the main Brazilian ports by using DEA to assess whether port efficiency is significantly affected by the nature of the cargo that is handled or the management model that is adopted. Their results showed no significant efficiency differences among different management models or types of cargo handled. Pagano et al. (2013) used SFA to compare the effectiveness of privatized Panamanian ports with US ports at varying degrees of privatization; their results estimated the savings and effectiveness gains from privatization.

Second, what are the factors that determine port efficiency? Numerous studies have focused on this issue. Scholars have attempted to examine how port efficiency is associated with variables that are related to management and/or policies (Notteboom et al. 2000; Tongzon and Heng 2005; Cullinane et al. 2005; Yuen et al. 2013; Serebrisky et al. 2016). Most of these studies have concluded that privatization and deregulation in the port sector positively affect efficiency (Cullinane et al. 2002; Cullinane and Song 2003; Barros and Athanassiou 2004; Pagano et al. 2013); For example, private-sector participation in Asian, European, and American container terminals has increased operational efficiency (Tongzon and Heng 2005). In contrast, other study argued that a clear-cut relationship between 
port ownership or management and efficiency could not be proven (Liu 1995; Notteboom et al. 2000; González and Trujillo 2009). According to an empirical study with a sample of 19 ports in North America and Europe, Valentine and Gray (2002) found that ownership does not significantly affect port efficiency.

Several studies have found that port efficiency increases significantly with port size, driven by economies of scale and agglomeration (Martínez-Budria et al. 1999; Notteboom et al. 2000; Barros 2006; De Oliveira and Cariou 2011; Schøyen and Odeck 2013). Barros and Athanassiou (2004) believed that scale is the main source of port efficiency. In addition, some studies examined the relationship between port efficiency and other factors, such as the geographical location and accessibility of the port (Liu 1995; Caldeirinha and Felicio 2011; Bergantino and Musso 2011), the port's competitive position (Haralambides et al. 2002; Defilippi and Flor 2008; Yuen et al. 2013; De Oliveira and Cariou 2015), the essential production factors (Dowd and Leschine 1990; Wan et al. 2014), and the economic level of the port hinterland (Tongzon 2002; Cheon 2007).

The above-cited studies mainly focused on the characteristics of seaport efficiency and its influencing factors by using a variety of research methods across different periods or regions. Few studies have addressed the river ports along the Yangtze or in other riverine areas of China and across the world. In fact, each river port system has its own dynamics, and its spatial and functional development is both location and time specific (Notteboom 2007). This paper focuses exclusively on the nature of port efficiency along the Yangtze, with a specific emphasis on the dynamic characteristics of technical efficiency and total factor productivity by using both the super-SBM model and Malmquist productivity index.

\section{Yangtze River port system}

The Yangtze River originates from the Tanggula Mountains on the Qinghai-Tibet Plateau. The river is $6397 \mathrm{~km}$ long, ${ }^{1}$ the longest river in Asia and the third longest in the world. The drainage area of the river is more than 1.8 million $\mathrm{km}^{2}$, accounting approximately one-fifth of China's land mass (Fig. 1). The river flows through three economic zones (eastern, central, and western) of China and plays an increasingly important socioeconomic and ecological role in China. Since the beginning of the 21st century, the YZREB has become the largest inland industrial belt and one of the most important manufacturing industry bases in the world (Yu et al. 2015). Meanwhile, as the region with the most developed economy and the highest degree of urban agglomeration in China, the Yangtze River Delta has developed into one of the most important foundations for economic growth. Against this background, the YRPS has transitioned into periods of sustained and rapid development. The ports along the Yangtze River handled over 2.5 billion tons of cargo in 2017, increasing

\footnotetext{
1 The mainstream waterway of the Yangtze River is around $2800 \mathrm{~km}$ and can be divided into three main reaches: the upper reach from Yichang to Yibin, the middle reach from Wuhan to Yichang, and the lower reach from Shanghai to Wuhan.
} 


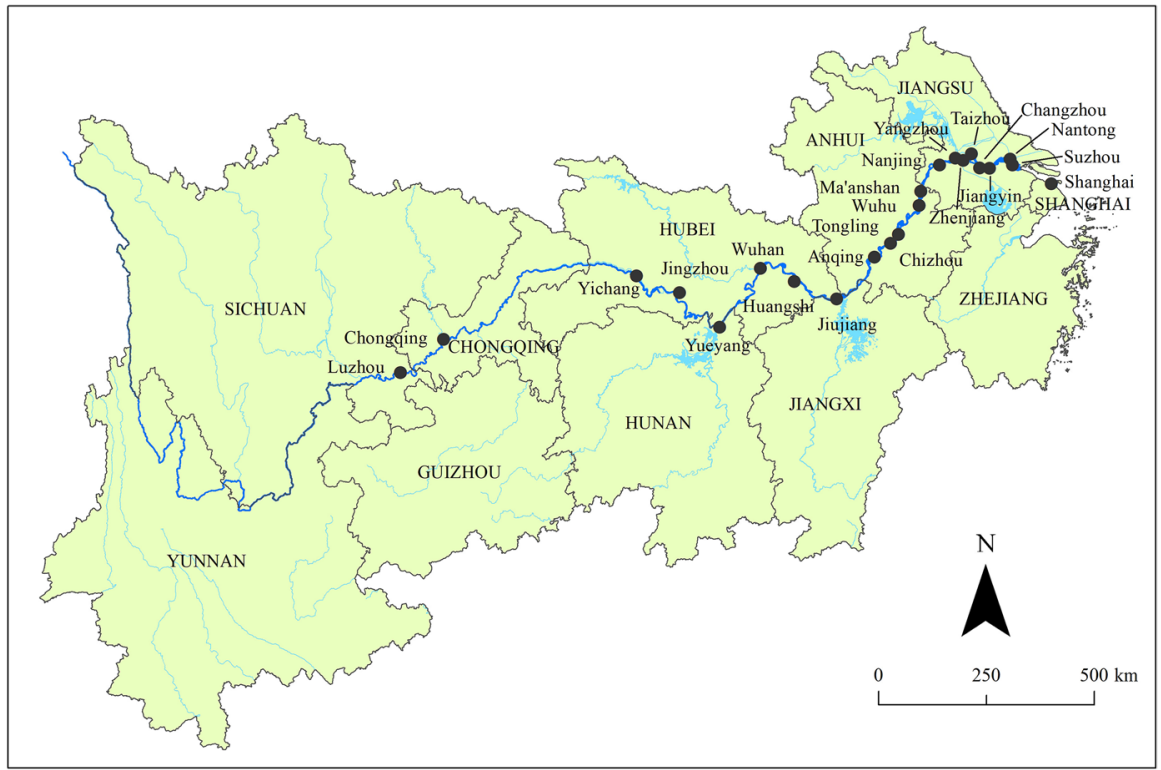

Fig. 1 Major ports along the Yangtze River

by more than $8.2 \%$ compared with the previous year ${ }^{2}$ and ranking first among the world's inland waterway ports. Given its strategic position for China and its critical role in the YZREB, the effective and sustainable development of the YRPS has attracted the interest of policymakers and scholars.

However, the ports along the Yangtze River have faced fiercer competition compared with seaports because of their proximity, overlapping hinterlands, and similar shipping conditions within specific areas of the inland waterway. Since the reform of China's port management system in 2001, all port authorities were devolved from the central government to various local governments, and the latter became the main bodies responsible for the investment, construction, and maintenance of port infrastructure. Subsequently, more port cities along the Yangtze River have joined the spree of port infrastructure construction, creating a serious excess of terminals.

At present, more than 3900 cargo berths are present on the mainstream waterway of the Yangtze River, of which 581 are 10,000-ton berths, measuring around 0.7 berths per kilometer of riverbank. ${ }^{3}$ This situation has caused the disorderly and inefficient utilization of riverbank resources and intensified hinterland competition among nearby ports (for instance, Yibin-Luzhou-Chongqing, Chongqing-Wuhan, Wuhu-Ma'anshan, and Nanjing-Suzhou). In addition, the development of the Yangtze River ports faces a series of problems: The shipping services sector and related maritime clusters have lagged, consolidation and distribution systems have become insufficient, management

\footnotetext{
2 http://finance.people.com.cn/n1/2018/0105/c1004-29746857.html.

${ }^{3}$ http://finance.people.com.cn/n1/2018/0518/c1004-29998355.html.
} 
practices have become inferior, etc. Accordingly, methods to improve the competitive environment and increase the production efficiency of ports have become a priority for the sustainable development of the YRPS.

\section{Methodology and data}

\subsection{Super-SBM model}

DEA is a nonparametric technique that is used in operations research and econometrics for multivariate frontier estimation and ranking. This approach can be utilized to calculate the relative efficiency levels within a group of decision-making units (DMUs) by comparing the relationship (distance) between a DMU and the efficient frontier (Panayides et al. 2009). In the field of port efficiency measurement, DEA has become one of the mainstream technical tools, offering remarkable advantages such as not requiring the adoption of a specific form of frontier production function, nonsubjective weights, and simple data requirements (Barros and Athanassiou 2004; Lai et al. 2012). However, traditional DEA models are radial and angular measurement methods, creating efficiency measurements that reflect equiproportional reductions in inputs or outputs onto the best-practice frontier (Farrell 1957). The accuracy of traditional DEA efficiency measurements is affected by the method's inability to consider input excesses and output shortfalls from inefficient DMUs (known as slacks). To overcome the shortcomings of traditional DEA, Tone (2001) proposed a slacks-based measure of efficiency (SBM), which is nonradial and directly handles input or output slacks. The SBM model can be interpreted as profit maximizing, in contrast to traditional DEA models such as the CCR model, which attempt to find the maximum ratio of the virtual output over the virtual input.

Consider a production system with $n$ homogeneous DMUs expressed as the input and output matrices $X=\left(x_{i j}\right) \in R^{m \times n}$ and $Y=\left(y_{i j}\right) \in R^{s \times n}$, respectively. Furthermore, all the inputs and outputs are assumed to be positive, i.e., $X>0$ and $Y>0$. The production possibility set $P$ is defined as

$$
P=\{(x, y) \mid x \geq X \lambda, y \leq Y \lambda, \lambda \geq 0\},
$$

where $\lambda$ is a nonnegative vector in $R^{n}$.

A certain DMU $\left(x_{0}, y_{0}\right)$ can be described as

$$
x_{0}=X \lambda+s^{-}, \quad y_{0} Y \lambda-s^{+},
$$

where $\lambda \geq 0$ and $s^{-}$and $s^{+}$indicate the input and output slack variables, respectively.

For the SBM model, the efficiency of a DMU $\left(x_{0}, y_{0}\right)$ can be measured by the following fractional problem:

$$
\min \rho=\frac{1-\frac{1}{m} \sum_{i=1}^{m} \frac{s_{j}^{-}}{x_{i 0}}}{1+\frac{1}{s} \sum_{i=1}^{s} \frac{s_{j}^{+}}{y_{i 0}}}
$$




$$
\begin{gathered}
\text { subject to } \quad x_{0}=X \lambda+s^{-} \\
y_{0}=Y \lambda-s^{+} \\
\lambda \geq 0, \quad s^{-} \geq 0, \quad s^{+} \geq 0,
\end{gathered}
$$

where the value of $\rho$ is the efficiency score at DMU $\left(x_{0}, y_{0}\right)$. A DMU $\left(x_{0}, y_{0}\right)$ is SBM-efficient if $\rho^{*}=1$, which means $s^{-^{*}}=s^{+^{*}}=0$.

To further compare and rank SBM-efficient DMUs, Tone (2002) proposed the super-efficiency SBM model, which is derived from the SBM model and the superefficiency DEA model that was proposed by Andersen and Petersen (1993). The superefficiency SBM model is described as

$$
\begin{gathered}
\delta^{*}=\min \delta=\frac{\frac{1}{m} \sum_{i=1}^{m} \frac{\bar{x}_{i}}{\frac{1}{x_{i 0}}} \sum_{r=1}^{s} \frac{\bar{y}_{r}}{x_{r 0}}}{\text { Subject to } \quad \bar{x} \geq \sum_{j=1, j \neq 0}^{n} \lambda_{j} x_{j}} \\
\bar{y} \geq \sum_{j=1, j \neq 0}^{n} \lambda_{j} y_{j} \\
\bar{x} \geq x_{0}, \quad \bar{y} \leq y_{0}, \quad \bar{y} \geq 0 ; \quad \lambda_{j} \geq 0, \quad j=1, \ldots, n .
\end{gathered}
$$

\subsection{Malmquist productivity index}

Although cross-sectional data enable one to track each producer and its efficiency through a sequence of periods, the results might contain bias arising from situations specific to the period under examination (Kumbhakar and Lovell 2000; Panayides et al. 2009). To overcome this inherent limitation, the Malmquist productivity index (MPI) has been proposed (Malmquist 1953; Caves et al. 1982; Färe et al. 1994) and has become the most widely applied approach for measuring changes in both efficiency and productivity over time (Cullinane et al. 2004).

The MPI is based on the Shephard distance function (Shephard 1970). Färe et al. (1994) defined distance functions with respect to two different periods and specified the output-based MPI as the geometric mean of two CCD-type MPIs (Caves et al. 1982):

$$
M_{0}\left(x^{t+1}, y^{t+1}, x^{t}, y^{t}\right)=\left[\frac{D_{\mathrm{o}}^{t}\left(x^{t+1}, y^{t+1}\right)}{D_{\mathrm{o}}^{t}\left(x^{t}, y^{t}\right)} \times \frac{D_{\mathrm{o}}^{t+1}\left(x^{t+1}, y^{t+1}\right)}{D_{\mathrm{o}}^{t+1}\left(x^{t}, y^{t}\right)}\right]^{1 / 2} .
$$


The index can be broken down into two components:

$$
M_{0}\left(x^{t+1}, y^{t+1}, x^{t}, y^{t}\right)=\frac{D_{\mathrm{o}}^{t}\left(x^{t+1}, y^{t+1}\right)}{D_{\mathrm{o}}^{t}\left(x^{t}, y^{t}\right)} \times\left[\frac{D_{\mathrm{o}}^{t}\left(x^{t+1}, y^{t+1}\right)}{D_{\mathrm{o}}^{t+1}\left(x^{t+1}, y^{t+1}\right)} \times \frac{D_{\mathrm{o}}^{t}\left(x^{t}, y^{t}\right)}{D_{\mathrm{o}}^{t+1}\left(x^{t}, y^{t}\right)}\right]^{1 / 2},
$$

where the ratio outside the brackets measures the changes in technical efficiency (i.e., the change in the distance of the observed production from the maximum potential production) between periods $t$ and $t+1$. The geometric mean of the two ratios inside the brackets measures the technological change (TC) between two periods evaluated at $x_{t}$ and $x_{t+1}$.

In addition, if strong disposability of inputs and outputs is assumed (Färe et al. 1994), the technical efficiency change (TEC) can be further decomposed into the pure technical efficiency change (PTEC) and scale efficiency change (SEC), where $\mathrm{TEC}=\mathrm{PTEC} \times \mathrm{SEC}$. The multiplicative decomposition of this index becomes

$$
\begin{aligned}
M_{0}\left(x^{t+1}, y^{t+1}, x^{t}, y^{t}\right)= & \frac{D_{\mathrm{o}}^{t+1}\left(x^{t+1}, y^{t+1} \mid \mathrm{VRS}\right)}{D_{\mathrm{o}}^{t}\left(x^{t}, y^{t} \mid \mathrm{CRS}\right)} \times \frac{D_{\mathrm{o}}^{t+1}\left(x^{t+1}, y^{t+1} \mid \mathrm{VRS}\right)}{D_{\mathrm{o}}^{t}\left(x^{t}, y^{t} \mid \mathrm{VRS}\right)} \\
& \times\left[\frac{D_{\mathrm{o}}^{t}\left(x^{t+1}, y^{t+1} \mid \mathrm{CRS}\right)}{D_{\mathrm{o}}^{t+1}\left(x^{t+1}, y^{t+1} \mid \mathrm{CRS}\right)} \times \frac{D_{\mathrm{o}}^{t}\left(x^{t}, y^{t} \mid \mathrm{CRS}\right)}{D_{\mathrm{o}}^{t+1}\left(x^{t}, y^{t} \mid \mathrm{CRS}\right)}\right]^{1 / 2},
\end{aligned}
$$

where CRS and VRS represent the constant returns to scale and the variable returns to scale assumptions, respectively. If $M>1$, productivity is improved. If $M<1$, productivity is reduced. If $M=1$, productivity remains unchanged.

\subsection{Data collection}

One critical issue in port efficiency measurement is sample selection. Although no explicit restrictions exist for the selection of ports, having competitive relationships among the selected ports is preferable in terms of efficiency measurement. With this approach, the ranking of relative efficiencies becomes more valuable and provides more references for the sustainable development of these ports (Panayides et al. 2009). In addition, Ali et al. (1989) and Bowlin (1987) both suggested that the number of DMUs should be at least twice the sum of the input and output variables. To serve the purpose of this study, 22 major ports along the Yangtze River ${ }^{4}$ were selected as a sample; their locations are depicted in Fig. 1. These ports, which are the primary nodes of the Yangtze River's shipping network, handle more than $90 \%$ of the cargo and container throughput of the Yangtze River Basin. The beadedstring-like distribution of these ports along the Yangtze River and their geographic proximity result in overlapping hinterlands. For a long time, these ports have both

\footnotetext{
4 The 22 sample ports: Luzhou, Chongqing, Yichang, Jingzhou, Yueyang, Wuhan, Huangshi, Jiujiang, Anqing, Chizhou, Tongling, Wuhu, Ma'anshan, Nanjing, Zhenjiang, Taizhou, Yangzhou, Jiangyin, Changzhou, Suzhou, Nantong, and Shanghai.
} 
competed and cooperated with each other in areas such as sources of goods, highend shipping talent, and shipping cluster by and large. One could reasonably label these ports as a close-knit organic whole.

While perusing earlier research, it was observed that the input and output variables that were used for measuring port efficiency were quite different. The most frequent input variables often related to the efficient use of land, labor, and capital (Dowd and Leschine 1990), e.g., length of berths, terminal areas, warehouse capacity, number of gantry cranes and employees, and quayside water depth (Tongzon 2001; Barros and Athanassiou 2004; Cullinane and Wang 2006b; Wu and Goh 2010; De Oliveira and Cariou 2011; Nguyen et al. 2018). At the same time, cargo throughput, container throughput, and number of ship calls have often been chosen as output variables (Valentine and Gray 2001; Itoh 2002; Barros and Athanassiou 2004; Cullinane et al. 2006; Beuren et al. 2018; Nguyen et al. 2018). These studies provide some referencing for the present study. However, we consider that inputs and outputs should accurately reflect the actual objectives and processes of port/terminal production, alongside the availability of data on the Yangtze River ports. Therefore, quay-wall length, number of berths, and channel (dredging) depth are used in the present work as inputs, and general cargo throughput and container throughput as outputs. ${ }^{5}$

Panel data for the 22 major ports in 2010, 2012, 2014, and 2016 were selected, giving a sample of 88 observations. The raw data were mainly obtained from the China Statistical Yearbook, the China Transportation and Communications Yearbook, and the China Ports Yearbook, each of which consider several issues. To solve the problem of data unavailability for some ports, data that were collected from the websites or annual reports of sampled ports and terminal operators were also incorporated into the final dataset. Some important statistics relating to the sample are summarized in Table 1.

\section{Results and discussion}

\subsection{Efficiency of the Yangtze River port system}

Based on this dataset, the efficiency characteristics of the Yangtze River port system in 2016 were estimated and compared by using the super-SBM DEA model of the MyDEA software package. The efficiency measurements are presented in Table 2.

These results show that the Yangtze River port system in 2016 had a relatively low average technical efficiency (TE) of 0.642 , at a great distance from the production

\footnotetext{
5 There is a statistical overlap between port cargo throughput and container throughput. Container throughput reflects the total number of import and export containers in a certain port over a period of time, including heavy and empty containers. The cargo throughput refers to the amount of cargo transported in and out of the port area by water, but it does not reflect the number of empty containers handled by the port. And this is critical to the port's production efficiency. Therefore, the simultaneous use of cargo throughput and container throughput as output variables in port efficiency calculations is a compromise approach under existing data conditions.
} 


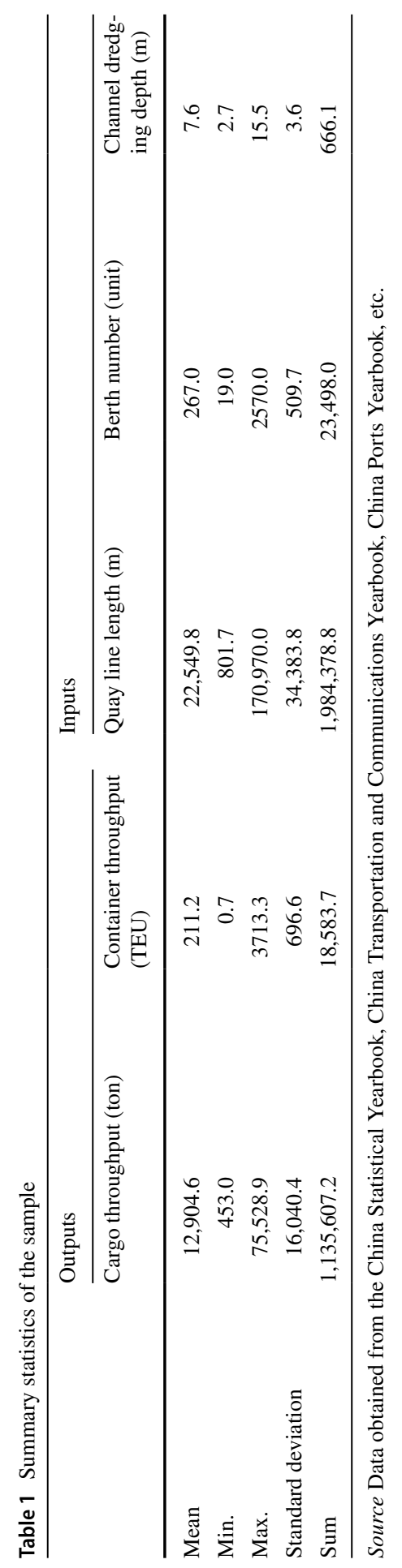


Table 2 The efficiency of the Yangtze River port system in 2016

\begin{tabular}{|c|c|c|c|c|c|c|}
\hline Location & Port & $\mathrm{TE}$ & PTE & SE & $\begin{array}{l}\text { Returns to } \\
\text { scale }\end{array}$ & Rank \\
\hline \multirow[t]{2}{*}{ Upper reach } & Luzhou & 0.219 & 1.085 & 0.202 & IRS & 19 \\
\hline & Chongqing & 0.370 & 0.478 & 0.775 & IRS & 15 \\
\hline \multirow[t]{6}{*}{ Middle reach } & Yichang & 0.149 & 1.001 & 0.149 & IRS & 21 \\
\hline & Jingzhou & 0.195 & 1.680 & 0.116 & IRS & 20 \\
\hline & Yueyang & 0.700 & 1.157 & 0.605 & IRS & 6 \\
\hline & Wuhan & 0.376 & 0.668 & 0.562 & IRS & 14 \\
\hline & Huangshi & 0.261 & 0.655 & 0.398 & IRS & 17 \\
\hline & Jiujiang & 0.459 & 0.730 & 0.629 & IRS & 11 \\
\hline \multirow[t]{16}{*}{ Lower reach } & Anqing & 0.120 & 0.425 & 0.283 & IRS & 22 \\
\hline & Chizhou & 0.241 & 0.536 & 0.449 & IRS & 18 \\
\hline & Tongling & 0.634 & 1.003 & 0.632 & IRS & 7 \\
\hline & Wuhu & 0.457 & 0.623 & 0.733 & IRS & 12 \\
\hline & Ma'anshan & 0.406 & 0.584 & 0.695 & IRS & 13 \\
\hline & Nanjing & 0.622 & 0.719 & 0.865 & IRS & 8 \\
\hline & Zhenjiang & 0.331 & 0.462 & 0.716 & IRS & 16 \\
\hline & Taizhou & 0.477 & 0.606 & 0.787 & IRS & 10 \\
\hline & Yangzhou & 1.007 & 1.009 & 0.998 & IRS & 4 \\
\hline & Jiangyin & 0.522 & 0.674 & 0.774 & IRS & 9 \\
\hline & Changzhou & 1.181 & 1.279 & 0.923 & IRS & 3 \\
\hline & Suzhou & 1.795 & 3.478 & 0.516 & DRS & 2 \\
\hline & Nantong & 0.887 & 0.893 & 0.993 & DRS & 5 \\
\hline & Shanghai & 2.714 & 1.000 & 2.714 & DRS & 1 \\
\hline & SD & 0.592 & 0.629 & 0.505 & & \\
\hline & Mean & 0.642 & 0.943 & 0.705 & & \\
\hline
\end{tabular}

IRS represents increasing returns to scale, and DRS represents decreasing returns to scale. TE, PTE, and SE represent the comprehensive technical efficiency, pure technical efficiency, and scale efficiency, respectively.

frontier. The ports of Shanghai $(\mathrm{TE}=2.714)$, Suzhou $(\mathrm{TE}=1.795)$, Changzhou $(\mathrm{TE}=1.181)$, and Yangzhou $(\mathrm{TE}=1.007)$ were the few ports with TEs greater than one, representing only 3 out of all 22 sample ports. The efficiency scores of other sample ports were significantly lower and did not exceed one, i.e., with plenty of room to improve efficiency through better resource utilization. The standard deviation of the YRPS's TE was 0.592, indicating obvious differences in the TE of these ports; For example, the TE of Shanghai (2.714) was around 23 times that of Anqing (0.120). Furthermore, the spatial distribution of the TEs of ports along the Yangtze River generally increased from the upper to lower reaches. This result is closely related to the unbalanced development of ports along the Yangtze River over a long period time, caused by great disparities in channel conditions, hinterland economies, consolidation and distribution systems, and government policies.

For the two decompositions of TE, the sample ports showed significant differences in scale efficiency (SE) and pure technical efficiency (PTE). Starting with 
SE, Shanghai showed the highest SE (2.714) and was the only port to achieve scale effectiveness, followed by Yangzhou, Nantong, and Changzhou (0.998, 0.993, and 0.923 , respectively). These three ports showed relatively high SEs and were very close to the optimal SE state. Moreover, the SEs of the remaining sample ports deviated from the optimal state to varying degrees. The standard deviation and mean of the SE were 0.505 and 0.705 , respectively, indicating that the SE of the Yangtze River port system demonstrates significant differences, and the actual production scales are quite far from optimal. The scale effect of the Yangtze River port system has not yet been fully realized. Compared with the SE, differences in the PTE were more pronounced: the standard deviation of the PTE was 0.629. Nine ports, including Suzhou (PTE = 3.478), Jingzhou (PTE = 1.680), Changzhou (PTE = 1.279), and Yueyang (PTE = 1.157), reached the optimal PTE level, comprising $40.9 \%$ of the sample ports, which was more than the number of ports with optimal TEs and SEs. The YRPS presented a relatively high average PTE (0.943), indicating that the PTE was very close to the optimal level and was affected by factors such as technology, operational modes, and enterprise management and decisions.

The penultimate column of Table 2 lists the positions of the 22 sample ports in the VRS frontier. The ports with decreasing returns to scale are Shanghai, Nantong, and Suzhou, comprising $13.6 \%$ of the sample ports. This result indicates that the development of these three ports, which are located near the Yangtze River Estuary, exceeded the optimal scale. In other words, under the premise of maintaining the current output level, input redundancy should restrict any improvements in the SE of these ports. The remaining ports all show increasing returns to scale, although in actual practice much of their (excess) capacity and resources, particularly in the middle and upper reaches of the Yangtze River, are dysfunctional and obsolete, a structural overcapacity problem caused by blind port competition in the past. Therefore, investing in resources is still an effective method to improve the SE of these ports, from the perspective of input-output ratio.

There is currently more capacity than is required to produce the current throughput level. However, in fact, much of the production capacity is actually backward or invalid, representing a structural overcapacity problem caused by the blind competition that has been going on for a long time.

Notably, the measurement results of the super-SBM DEA model mainly reflect the relative efficiency characteristics and rankings of different ports in the port system. The measurement results imply that most of the Yangtze River ports (except for Shanghai, Nantong, and Suzhou) should increase their resource inputs to improve SE. However, this approach seems to be inappropriate from the perspective of the sustainable development of ports. Since the devolution of port management in 2001, the port cities along the Yangtze River have invested blindly in terminal facilities to improve their competitiveness and seize the sources of goods from nearby ports. Currently, a large number of terminals exist along the Yangtze River, but the proportion of small, chaotic, scattered, and weak terminals is obviously high. Currently, more than 2700 terminal operators have obtained terminal operation permits along the Yangtze River, of which only about 70 have a cargo throughput of more than 5 million tons (CPHA 2017). At the same time, this situation introduces a series of issues into the YRPS, such as overlapping of port functions, structural surplus of 


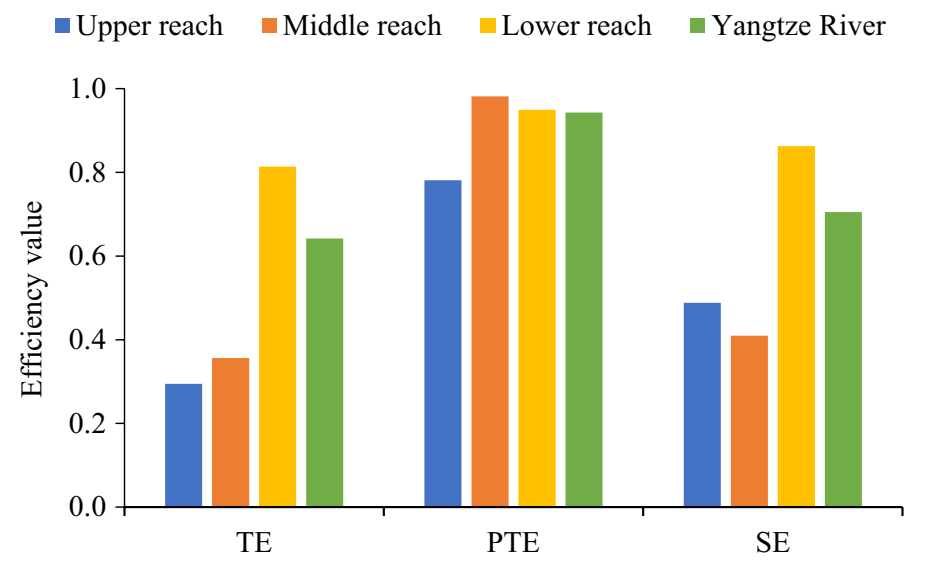

Fig. 2 Efficiency of three main port groups in 2016

cargo handling capacity, extensive utilization of riverbanks, and environmental damage. Therefore, investment in resources should focus on expanding the number and scale of terminals and pay more attention to the optimization of production capacity structures, the upgrading of terminal equipment, the improvement of consolidation and distribution systems, channel regulation, and the informatization construction of terminals to maintain the sustainable development of most ports along the Yangtze River.

The 22 river ports can be divided into three main port groups based on their geographic location: the upper-reach port group, the middle-reach port group, and the lower-reach port group. The comparative relationships of the TE, PTE, and SE of each port group are presented in Fig. 2, showing a clear gap in the average TE and its subcategories among each of the port groups. First, the average TE of the upper- and middle-reach port groups was 0.295 and 0.357 , respectively, far below that of the lower-reach port group $(\mathrm{TE}=0.814)$ and the average for the entire YRPS (TE $=0.642$ ). Thus, the weakness in the TE of the YRPS mainly lies in the upperand middle-reach port groups. Second, the three port groups were relatively balanced in terms of the average PTE. On average, the middle-reach port group had the highest PTE (0.982), slightly surpassing those of the lower-reach port group (0.949) and the entire YRPS (0.943). This result indicates that the middle-reach port group has certain advantages in aspects such as technology, operational modes, and enterprise management. Third, the lower-reach port group showed the best performance, with an average SE of 0.863 . The average SE of the middle-reach port group was only 0.410 , making this group the worst-performing port group and indicating that the scale benefits of this group were very limited. The SE offset the PTE, reducing the average TE of the middle-reach port group. 
Table 3 Average values of MPI and its subcategories for the Yangtze River port system in 2010-2016

\begin{tabular}{lllll}
\hline Period & MPI & \multicolumn{3}{l}{ MPI decomposition } \\
\cline { 3 - 5 } & & TC & PTEC & SEC \\
\hline $2010-2012$ & 1.153 & 1.105 & 1.04 & 1.004 \\
$2012-2014$ & 1.083 & 0.948 & 0.997 & 1.146 \\
$2014-2016$ & 1.148 & 1.187 & 0.997 & 0.969 \\
Mean & 1.128 & 1.075 & 1.011 & 1.037 \\
\hline
\end{tabular}

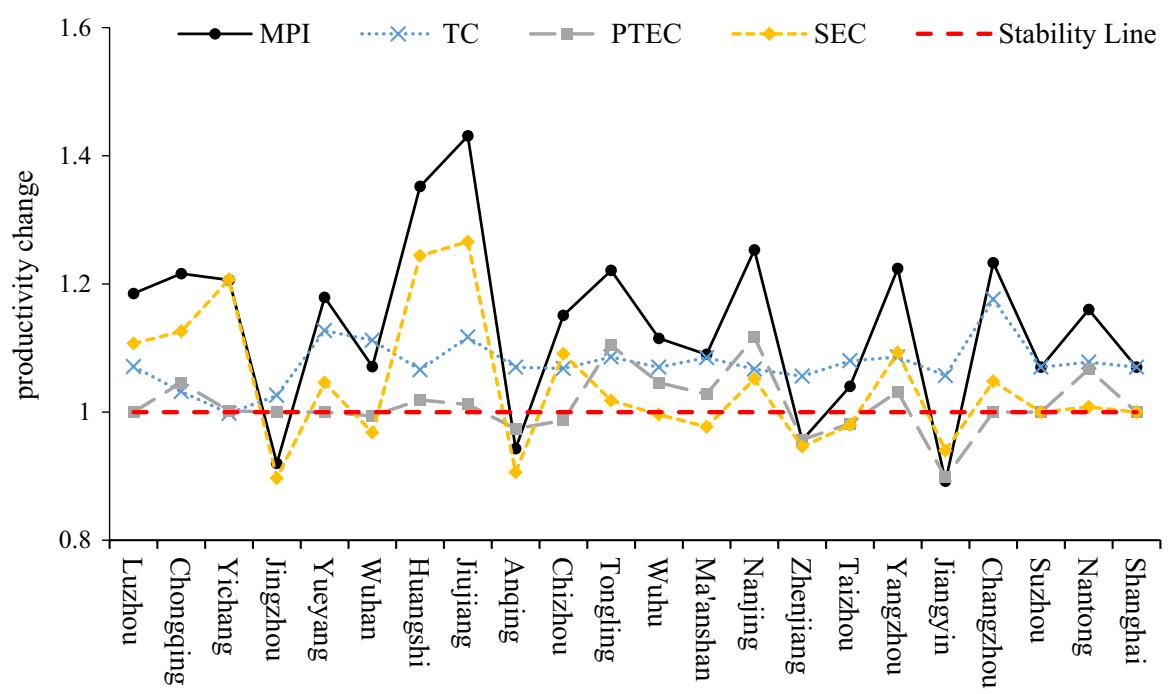

Fig. 3 Average values of MPI and its decomposition (2010-2016, in order of geographic location along the Yangtze River)

\subsection{Dynamic characteristics of the Yangtze River port system's efficiency}

Based on the above analysis, we attempted to deepen our understanding of the characteristics of the changes in the efficiency of the YRPS from a dynamic perspective. Hence, the MPI was used to estimate the changes in TFP for the YRPS, from 2010 to 2016. Table 3 presents the calculations of the MPI and its three decompositions, namely PTEC, TC, and SEC, for the periods 2010-2012, 2012-2014, and 2014-2016.

These results show that the sample ports experienced a significant improvement of $12.8 \%$ in their MPI between 2010 and 2016. The TC, PTEC, and SEC increased by $7.5 \%, 1.1 \%$, and $3.7 \%$, respectively. The results also suggest that the production technology, resource utilization, enterprise management, and scale economies in the YRPS improved throughout the study period, significantly improving the total factor productivity. 
Table 4 Correlation coefficient values of MPI and its sources of efficiency change

\begin{tabular}{lcll}
\hline Period & MPI-TC & MPI-PTEC & MPI-SEC \\
\hline 2010-2012 & 0.091 & $0.597^{* *}$ & $0.905^{* *}$ \\
2012-2014 & -0.100 & 0.285 & $0.782^{* *}$ \\
$2014-2016$ & $0.667^{* *}$ & 0.362 & $0.908^{* *}$ \\
\hline
\end{tabular}

**5\% significance level

Table 3 also presents the varying changes in the productivity levels of the MPI and its subcategories in the different study periods. The TFP rose consistently throughout the study period. Between 2012 and 2014, TC witnessed a decline in productivity. A slight deterioration in PTEC also occurred after 2012. Finally, a decrease in SEC was also recorded in 2014-2016, meaning that the main sources of TFP increases in the YRPS were different in each period. The 2010-2012 period showed the joint influence of TC, PTEC, and SEC; 2012-2014 showed the influence of SEC; and 2014-2016 showed the influence of TC. Figure 3 depicts the average MPI values and the three decompositions for the 22 sample ports from 2010 to 2016 (the nodes on the horizontal axis are arranged from left to right by their geographic location along the Yangtze River). The differences between sample ports in terms of their MPI and SEC were quite significant, while the differences in TC and PTEC were relatively minor. At the same time, the broken lines in Fig. 3 were located mostly above the stability line (equal to one), signifying that the sample ports performed well in terms of their MPI and its subcategories. Except for Yichang $(\mathrm{TC}=0.998)$, the $\mathrm{TC}$ of the other ports were higher than one, indicating that the production technology of the YRPS has generally improved in recent years and has become an important source of port efficiency. The PTEC and SEC of Wuhan, Anqing, Zhenjiang, Taizhou, and Jiangyin were all lower than one. Furthermore, four ports were below the stability line, namely Chizhou $(\mathrm{PTEC}=0.987$ ) for PTEC and Jingzhou (SEC $=0.897)$, Wuhu $($ SEC $=0.968)$, and Ma' anshan $(\mathrm{SEC}=0.977)$ for SEC, meaning that these ports showed a trend of deteriorating operational management or resource allocation. This finding should be seriously considered by local port management. Finally, apart from Jingzhou (MPI $=0.92$ ), Anqing (MPI $=0.943)$, Zhenjiang (MPI $=0.956)$, and Jiangyin $(\mathrm{MPI}=0.892)$, the MPI of the remaining 18 ports was higher than one. From high to low, the productivity growth rates of the sample ports were Jiujiang (MPI $=1.431$ ), Huangshi (MPI $=1.352)$, Nanjing $(\mathrm{MPI}=1.253)$, Changzhou $(\mathrm{MPI}=1.233)$, Yangzhou (MPI $=1.224)$, Tongling $(\mathrm{MPI}=1.221)$, Chongqing $(\mathrm{MPI}=1.216)$, Yichang (MPI $=1.206$ ), Luzhou (MPI $=1.185)$, Yueyang (MPI $=1.179)$, Nantong (MPI = 1.16), Chizhou (MPI = 1.151), Wuhu (MPI = 1.115), Ma' anshan (MPI = 1.09), Wuhan (MPI = 1.071), Suzhou (MPI = 1.07), Shanghai (MPI = 1.07), Taizhou (MPI = 1.04), Zhenjiang (MPI $=0.956)$, Anqing (MPI = 0.943), Jingzhou $(\mathrm{MPI}=0.92)$, and Jiangyin (MPI $=0.892)$. 
Analysis of the changes in the correlation coefficient between the MPI and its decompositions in different periods could provide a statistical basis for understanding the reasons for the changes in TFP. In Table 4, the productivity gains that were achieved from TC only had a statistically meaningful effect (at the $5 \%$ significance level) on the improvement in TFP in 2014-2016. In recent years, under active encouragement from the Ministry of Transport and the port administrative departments along the Yangtze River, port transformation and upgrading strategies 6 have achieved certain notable, albeit preliminary, results. Improvements in production technology played an increasingly significant role in the TFP improvement of the YRPS. The results show that PTEC had a stronger effect on TFP in 2010-2012, which was then followed by periods in which its effect was no longer significant (2012-2014 and 2014-2016). Changes in resource allocation, operational management, and business decisions, represented by PTEC, are believed to be important factors affecting port efficiency. However, we found that the effect of PTEC on the improvement of the overall efficiency of the YRPS greatly declined after 2012, which is not encouraging for the healthy development of river ports. Finally, the correlation coefficients between SEC and TFP were numerically larger, each at a statistical significance level of $5 \%$ in the three study periods. In other words, productivity gains from SE were the primary means to improve the TFP of the YRPS. Continuous input (resource) increases appeared to remain a reasonable approach from a statistical perspective. The above findings reveal that the improvement in the overall efficiency of the YRPS heavily depended on the scale benefits from the long-term extensive development of infrastructure, rather than from more strategic improvements in PTE.

\section{Conclusions}

The aim of this study is to measure the efficiency of the Yangtze River port system by using the super-SBM model and Malmquist productivity index. Twentytwo major ports along the Yangtze River were sampled, with the quay-wall length, number of berths, and channel (dredging) depth used as the input variables, and the cargo throughput and container throughput used as the output variables. Several conclusions can be drawn based on this analysis.

The results of the super-SBM model showed that the overall efficiency of the YRPS was on the low side; only four ports (Shanghai, Suzhou, Changzhou, and Yangzhou) achieved optimal TE. The management and utilization of inputs

\footnotetext{
6 The transformation and upgrading strategies of the Yangtze River ports involve several aspects: (a) promotion of port specialization, intensive development, and the integration of resources such as port terminals, river banks, and routes; (b) strengthening of the division and cooperation among ports, promotion of the coordinated development of ports in the upper, middle and lower reaches; encouragement of large-scale port and shipping enterprises to merge; and reorganization or formation of strategic alliances across regions, with capital, technology, and management as the link; and (c) strengthening the convergence between port planning, industrial development planning, and urban master planning, and promotion of the coordinated development of ports, riverside development zones and logistics parks.
} 
(resources) must improve (Table 2). The TE, SE, and PTE were obviously not equal among ports or port groups. The TE generally increased from the upper to lower reaches. Currently, Shanghai, Nantong, and Suzhou demonstrate decreasing returns to scale; in the future, these ports should transform from relying on resource consumption to efficient resource adoption, technological advancement, and institutional innovation. The remaining 19 river ports are still in the stage of increasing returns to scale. While expanding, these ports should intensify efforts to optimize production capacity structures, upgrade terminal equipment, improve consolidation and distribution systems, channel regulations, and strengthening information sharing among terminals.

The MPI results showed that the YRPS had differing degrees of improvement in its TFP, PTEC, TC, and SEC from 2010 to 2016 (Table 3). The improvement in TFP was the most obvious, with an increase of $12.8 \%$. However, the PTE of the YRPS showed a continuous downward trend after 2012, which must be considered. At the port level, except for Jingzhou, Anqing, Zhenjiang, and Jiangyin, the TFP of all the remaining 18 ports showed an increasing trend during the study period. TC became an important factor that affected the improvement of TFP after 2014, and the effect of PTEC became insignificant after 2012. At the same time, productivity gains from SEC were the main means to improve the TFP of the YRPS throughout the study period.

These results highlight the serious challenges that have impeded the sustainable development of the YRPS in recent years. These issues have raised considerable concern amongst government authorities at all levels, which are actively promoting the transformation, upgrading, and coordinated development of the YRPS by shutting down or relocating small terminals, integrating riverbank line resources, reforming terminal technologies, and setting up provincial-level port groups. However, in spite of the influence of the current administrative and management systems of ports, a performance evaluation system which utilizes economic improvement as its core and the trend of "government entrepreneuralization" (Zhang et al. 2006), excessive competition, and product homogeneity problems still exist among ports along the Yangtze River, and the coordinated development of these ports is generally low. This scenario has greatly reduced the efficiency and overall competitiveness of the YRPS.

Based on the present paper's findings, the efficiency of the YRPS can be improved through the following approaches: (1) Accelerate the planning and construction of consolidation and distribution systems along the Yangtze River, including upgrading multimodal transport infrastructures, increasing the number of river-crossing tunnels and bridges, optimizing the locations of dry ports, and improving the informatization level of inland navigation. (2) Drawing on the experience of the "Yangtze River Strategy"7 of the Shanghai International Port (Group) Co., Ltd., encourage more large-size port operators, shipping companies, and cargo owners to conduct cross-regional mergers, acquisitions, or informal strategic partnerships of port and shipping enterprises along the river, with capital, technology, and management as

${ }^{7}$ http://www.ship.sh/news_detail.php?nid=25504. 
the links. Strive to extend port services functions and improve the management and capabilities of terminal operators in the upper and middle Yangtze River. (3) Actively promote the integration of ports along the Yangtze River and establish a more stringent riverbank line development. Strengthen the joint construction and sharing of infrastructures (for instance, terminals, navigation waterways, anchorages, etc.) and aim at a more intensive utilization of public resources in ports. (4) Optimize the transportation network along the Yangtze River, based on a hub-andspoke concept, with Shanghai (at the mouth of the Yangtze) as the international hub port; Chongqing (located in the upper reach), Wuhan (located in the middle reach), and Nanjing (located in the lower reach) as regional hub ports; and the remaining river ports as feeder ports. The network should offer frequent services in the upper and middle Yangtze River after transshipment in the regional hub ports, utilizing relatively large vessels to and from Shanghai, thereby strengthening the division (as well as the cooperation) between large, medium, and small ports. Such an approach would fully utilize scale effects, improve transport efficiency, and reduce total costs (including transportation and time costs).

Overall, we hope that the present study has provided insights into the efficiency characteristics of Yangtze River ports, thus aiding both operational and policy decision-making to improve river port efficiency. However, we did not include labor, land, and information among our input indicators, being limited by the difficulty of port data acquisition, something that may have influenced our results. Enriching data sources, conducting efficiency studies from a terminal-scale perspective, identifying the critical factors influencing port efficiency, and exploring the optimization and upgrading paths of port efficiency may be important directions for future research.

Acknowledgements The authors would like to thank the anonymous referees and the Editor-in-Chief of $M E L$ for their careful reading and constructive suggestions. This research is supported by the Natural Sciences Foundation of China (grant nos. 41901138 and 41771139) and Program of Humanities and Social Sciences of the Ministry of Education of China (19YJCZH225).

Open Access This article is licensed under a Creative Commons Attribution 4.0 International License, which permits use, sharing, adaptation, distribution and reproduction in any medium or format, as long as you give appropriate credit to the original author(s) and the source, provide a link to the Creative Commons licence, and indicate if changes were made. The images or other third party material in this article are included in the article's Creative Commons licence, unless indicated otherwise in a credit line to the material. If material is not included in the article's Creative Commons licence and your intended use is not permitted by statutory regulation or exceeds the permitted use, you will need to obtain permission directly from the copyright holder. To view a copy of this licence, visit http://creativecommons.org/licen ses/by/4.0/.

\section{References}

Ali, I.A., A. Charnes, W.W. Cooper, D. Divine, and J. Stutz. 1989. An application of data envelopment analysis to management of US Army recruitment districts. In Applications of management science, a research annual, ed. R.L. Schultz. New York: JAI Press.

Andersen, P., and N.C. Petersen. 1993. A procedure for ranking efficient units in data envelopment analysis. Management Science 39 (10): 1261-1264. 
Barros, C.P. 2003. Incentive regulation and efficiency of Portuguese port authorities. Maritime Economics and Logistics 5 (1): 55-69.

Barros, C.P. 2006. A benchmark analysis of Italian seaports using data envelopment analysis. Maritime Economics and Logistics 8 (4): 347-365.

Barros, C.P., and M. Athanassiou. 2004. Efficiency in European seaports with DEA: Evidence from Greece and Portugal. Maritime Economics and Logistics 6 (2): 122-140.

Barros, C.P., Z. Chen, and P. Wanke. 2016. Efficiency in Chinese seaports: 2002-2012. Maritime Economics and Logistics 18 (3): 295-316.

Bergantino, A.S., and E. Musso. 2011. The role of external factors versus managerial ability in determining seaports' relative efficiency: an input-by-input analysis through a multi-step approach on a panel of Southern European ports. Maritime Economics and Logistics 13 (2): 121-141.

Beuren, M.M., R. Andriotti, G.B.B. Vieira, J.L.D. Ribeiro, and F.J.K. Neto. 2018. On measuring the efficiency of Brazilian ports and their management models. Maritime Economics and Logistics 20 (1): 149-168.

Bowlin, W.F. 1987. Evaluating the efficiency of US Air Force real-property maintenance activities. Journal of the Operational Research Society 38 (2): 127-135.

Caldeirinha, V.R., and J.A. Felicio. 2011. The influence of characterizing factors on port performance, measured by operational, financial and efficiency indicators. MPRA paper, 1 April. http://mpra. ub.uni-muenchen.de/30009/. Accessed 11 Nov 2018.

Caves, D.W., L.R. Christensen, and W.E. Diewert. 1982. The economic theory of index numbers and the measurement of input, output, and productivity. Econometrica 50 (6): 1393-1414.

Cheon, S. 2007. Evaluating impacts of institutional reforms on port efficiency changes Malquimist productivity index for world container ports. Berkeley: University of California.

Chin, A., and J. Tongzon. 1998. Maintaining Singapore as a major shipping and air transport hub. In Competitiveness of the Singapore economy: a strategic perspective, ed. T.M. Heng and T.K. Yam, 83-114. Singapore: Singapore University Press, World Scientific.

Coto-Millan, P., J. Banos-Pino, and A. Rodriguez-Alvarez. 2000. Economic efficiency in Spanish ports: some empirical evidence. Maritime Policy and Management 27 (2): 169-174.

China Ports and Harbours Association (CPHA). 2017. Current situation: Port transformation and upgrading on the road. China Ports 32 (3): 10-13.

Cullinane, K., and D.W. Song. 2003. A stochastic frontier model of the productive efficiency of Korean container terminals. Applied Economics 35 (3): 251-267.

Cullinane, K., and T.F. Wang. 2006a. Data envelopment analysis (DEA) and improving container port efficiency. Research in Transportation Economics 17: 517-566.

Cullinane, K., and T.F. Wang. 2006b. The efficiency of European container ports: a cross-sectional data envelopment analysis. International Journal of Logistics: Research and Applications 9 (1): 19-31.

Cullinane, K., D.W. Song, and R. Gray. 2002. A stochastic frontier model of the efficiency of major container terminals in Asia: assessing the influence of administrative and ownership structures. Transportation Research Part A: Policy and Practice 36 (8): 743-762.

Cullinane, K., D.W. Song, and T. Wang. 2005. The application of mathematical programming approaches to estimating container port production efficiency. Journal of Productivity Analysis 24 (1): 73-92.

Cullinane, K., D.W. Song, P. Ji, and T.F. Wang. 2004. An application of DEA windows analysis to container port production efficiency. Review of Network Economics 3 (2): 184-206.

Cullinane, K., T.F. Wang, D.W. Song, and P. Ji. 2006. The technical efficiency of container ports: comparing data envelopment analysis and stochastic frontier analysis. Transportation Research Part A: Policy and Practice 40 (4): 354-374.

Da Silva, F.G.F., and C.H. Rocha. 2012. A demand impact study of southern and southeastern ports in Brazil: an indication of port competition. Maritime Economics and Logistics 14 (2): 204-219.

De Monie, G. 1987. Measuring and evaluating port performance and productivity. Monographs on port management no. 6. Geneva, Switzerland: United Nations Conference On Trade And Development (UNCTAD).

De Oliveira, G.F., and P. Cariou. 2011. A DEA study of the efficiency of 122 iron ore and coal ports and of 15/17 countries in 2005. Maritime Policy and Management 38 (7): 727-743.

De Oliveira, G.F., and P. Cariou. 2015. The impact of competition on container port (in) efficiency. Transportation Research Part A: Policy and Practice 78: 124-133.

Defilippi, E., and L. Flor. 2008. Regulation in a context of limited competition: a port case. Transportation Research Part A: Policy and Practice 42 (5): 762-773. 
Dowd, T.J., and T.M. Leschine. 1990. Container terminal productivity: a perspective. Maritime Policy and Management 17 (2): 107-112.

Drewe, P., and B. Janssen. 1998. What port for the future? From 'Mainports' to ports as nodes of logistic networks. In Accessibility, trade and locational behaviour, ed. A. Reggiani, 241-264. Aldershot: Ashgate.

Färe, R., S. Grosskopf, M. Norris, and Z.Y. Zhang. 1994. Productivity growth, technical progress, and efficiency change in industrialized countries. The American Economic Review 84 (1): 66-83.

Farrell, M.J. 1957. The measurement of productive efficiency. Journal of the Royal Statistical Society 120 (3): 253-290.

González, M.M., and L. Trujillo. 2008. Reforms and infrastructure efficiency in Spain's container ports. Transportation Research Part A: Policy and Practice 42 (1): 243-257.

González, M.M., and L. Trujillo. 2009. Efficiency measurement in the port industry: a survey of the empirical evidence. Journal of Transport Economics and Policy 43 (2): 157-192.

Haralambides, H.E., P. Cariou, and M. Benacchio. 2002. Costs, benefits and pricing of dedicated container terminals. International Journal of Maritime Economics 4 (1): 21-34.

Itoh, H. 2002. Efficiency changes at major container ports in Japan: a window application of data envelopment analysis. Review of Urban and Regional Development Studies 14 (2): 133-152.

Kumbhakar, S.C., and C.A.K. Lovell. 2000. Stochastic frontier analysis. Cambridge: Cambridge University Press.

Lai, P.L., A. Potter, and M. Beynon. 2012. The development of benchmarking techniques in airport performance evaluation research. Transportation Journal 51 (3): 305-337.

Liu, Z. 1995. The comparative performance of public and private enterprises: the case of British ports. Journal of Transport Economics and Policy 29 (3): 263-274.

Malmquist, S. 1953. Index numbers and indifference surfaces. Trabajos de Estadística 4 (2): 209-242.

Martínez-Budria, E., R. Diaz-Armas, M. Navarro-Ibanez, and T. Ravelo-Mesa. 1999. A study of the efficiency of Spanish port authorities using data envelopment analysis. International Journal of Transport Economics 26 (2): 237-253.

Merkel, A., and J. Holmgren. 2017. Dredging the depths of knowledge: efficiency analysis in the maritime port sector. Transport Policy 60: 63-74.

Nguyen, H.O., H.S. Nghiem, and Y.T. Chang. 2018. A regional perspective of port performance using metafrontier analysis: the case study of Vietnamese ports. Maritime Economics and Logistics 20 (1): $112-130$.

Notteboom, T. 2007. Container river services and gateway ports: Similarities between the Yangtze River and the Rhine River. Asia Pacific Viewpoint 48 (3): 330-343.

Notteboom, T., C. Coeck, and J. Van Den Broeck. 2000. Measuring and explaining the relative efficiency of container terminals by means of Bayesian stochastic frontier models. International Journal of Maritime Economics 2 (2): 83-106.

Pagano, A.M., G.W. Wang, O.V. Sánchez, and R. Ungo. 2013. Impact of privatization on port efficiency and effectiveness: results from Panama and US ports. Maritime Policy and Management 40 (2): $100-115$.

Panayides, P.M., C.N. Maxoulis, T.F. Wang, and K.Y.A. Ng. 2009. A critical analysis of DEA applications to seaport economic efficiency measurement. Transport Reviews 29 (2): 183-206.

Robinson, R. 2002. Ports as elements in value-driven chain systems: The new paradigm. Maritime Policy and Management 29 (3): 241-255.

Kim, M., and A. Sachish. 1986. The structure of production, technical change and productivity in a port. The Journal of Industrial Economics 35 (2): 209-223.

Schøyen, H., and J. Odeck. 2013. The technical efficiency of Norwegian container ports: A comparison to some Nordic and UK container ports using Data Envelopment Analysis (DEA). Maritime Economics and Logistics 15 (2): 197-221.

Serebrisky, T., J.M. Sarriera, A. Suárez-Alemán, G. Araya, C. Briceño-Garmendía, and J. Schwartz. 2016. Exploring the drivers of port efficiency in Latin America and the Caribbean. Transport Policy 45: 31-45.

Shephard, R. 1970. Theory of cost and production functions. Princeton: Princeton University Press.

Suykens, F., and E. Van de Voorde. 1998. A quarter a century of port management in Europe: objectives and tools. Maritime Policy and Management 25 (3): 251-261.

Tone, K. 2001. A slacks-based measure of efficiency in data envelopment analysis. European Journal of Operational Research 130 (3): 498-509. 
Tone, K. 2002. A slacks-based measure of super-efficiency in data envelopment analysis. European Journal of Operational Research 143 (1): 32-41.

Tongzon, J. 2001. Efficiency measurement of selected Australian and other international ports using data envelopment analysis. Transportation Research Part A: Policy and Practice 35 (2): 107-122.

Tongzon, J. 2002. Port choice determinants in a competitive environment. In Annual IAME meeting and conference, Panama, 1-22 November.

Tongzon, J., and W. Heng. 2005. Port privatization, efficiency and competitiveness: some empirical evidence from container ports (terminals). Transportation Research Part A: Policy and Practice 39 (5): 405-424.

Tongzon, J.L. 1995. Determinants of port performance and efficiency. Transportation Research Part A: Policy and Practice 29 (3): 245-252.

Valentine, V.F., and R. Gray. 2001. The measurement of port efficiency using data envelopment analysis. In Proceedings of the 9th world conference on transport research, Seoul, 22-27 July.

Valentine, V.F., and R. Gray. 2002. An organisational approach to port efficiency. In Proceedings of IAME Panama 2002 conference, Panama, 13-15 November.

Verhoeven, P. 2010. A review of port authority functions: towards a renaissance? Maritime Policy and Management 37 (3): 247-270.

Wan, Y., A.C.L. Yuen, and A. Zhang. 2014. Effects of hinterland accessibility on US container port efficiency. International Journal of Shipping and Transport Logistics 56 (4): 422-440.

Wang, T.F., and K. Cullinane. 2006. The efficiency of European container terminals and implications for supply chain management. Maritime Economics and Logistics 8 (1): 82-99.

Wang, T.F., K.P.B. Cullinane, and D.W. Song. 2004. Industrial concentration in container ports. In Proceedings of IAME Izmir 2004 conference, 30 June-2 July.

Wu, Y.C.J., and M. Goh. 2010. Container port efficiency in emerging and more advanced markets. Transportation Research Part E: Logistics and Transportation Review 46 (6): 1030-1042.

Yu, X.G., L. Wang, Q.K. Yang, and S.L. Ye. 2015. Background of the Yangtze River economic belt development strategy and geography interpretation of its innovative development. Progress in Geography 34 (11): 1368-1376.

Yuen, A.C.L., A. Zhang, and W. Cheung. 2013. Foreign participation and competition: a way to improve the container port efficiency in China? Transportation Research Part A: Policy and Practice 49: 220-231.

Zhang, J.X., J. Yin, and X.L. Luo. 2006. Research of urban spatial development under the circumstances of local government's entrepreneuralization. Human Geography 21 (4): 1-6.

Zhao, Y.R., Z.Z. Yang, and H. Haralambides. 2019. Optimizing the transport of export containers along China's coronary artery: the Yangtze River. Journal of Transport Geography 77: 11-25.

Publisher's Note Springer Nature remains neutral with regard to jurisdictional claims in published maps and institutional affiliations. 